\title{
ABSI - The Voice for Breast Surgery in India; Celebrating 10 positively eventful years! (2011 - 2021)
}

\author{
From the desk of the Sectional Editor, IJS - Special Issue on "Breast"
}

\author{
Raghu Ram Pillarisetti OBE ${ }^{1}$. S. P. Somashekhar ${ }^{2}$
}

Published online: 30 October 2021

(c) Association of Surgeons of India 2021

\section{Introduction and Aims}

\section{"Everything begins with a story"}

Established in 2011, the Association of Breast Surgeons of India (ABSI) is celebrating 10 positively eventful years and has rapidly emerged to become the "Voice for "Breast Surgery" in India. To commemorate this milestone, the Indian Journal of Surgery has brought out a special issue on "Breast", which showcases contributions from across the country in addition to a few invited articles from overseas. I am delighted that this issue has been published during the Presidential tenure of dear friend, Prof. S.P. Somashekhar, who has been the "backbone" for the Association from day 1.

The thought of establishing a dedicated Breast Surgical Society in India began almost two decades ago, in the year 2002. This was the year my mother was diagnosed with breast cancer. Having obtained higher surgical training and subspecialty training in breast surgery at world renowned centres of excellence in the UK, and equally, much as I had rewarding career opportunities in the British Isles, I took a conscious decision with my family to leave everything "lock, stock and barrel" to take care of my mother and serve my motherland. This was well and truly "The Major Turning Point" [1, 2].

Raghu Ram Pillarisetti OBE

p.raghuram@hotmail.com

1 KIMS-USHALAKSHMI Centre for Breast Diseases, KIMS Hospitals, Hyderabad, India

2 ABSI, Manipal Cancer Centre, Bangalore, India

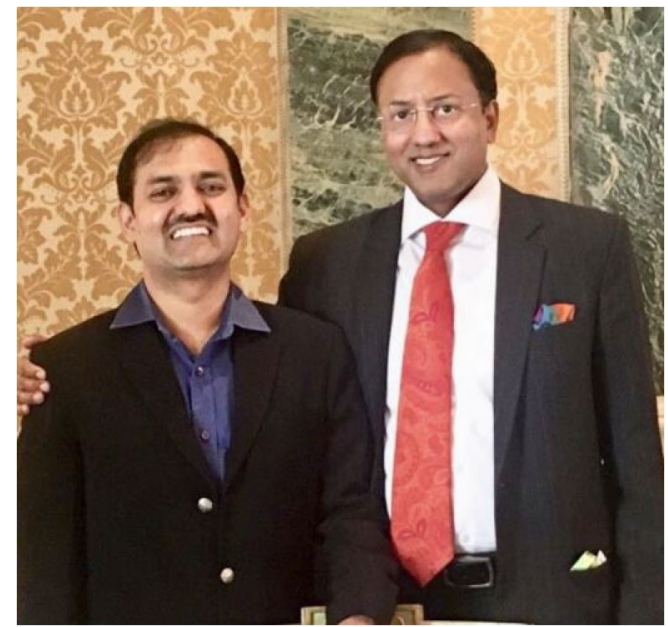

With Prof. S.P. Somashekhar, President ABSI (2019-2021)

It was during this transition phase of my life that I happened to meet up with Prof. Devendra Patel, who had come over to the UK in 2004 to attend the annual scientific Congress of the British Association of Surgical Oncology (BASO). I shared with him my thoughts of relocating to India and concrete plans to establish a dedicated Breast Centre and a Breast Cancer Charity in Hyderabad.

I had also pointed out to him the need to form an organisation similar to the Association of Breast Surgery at BASO that brings together surgeons practicing the art and science of breast surgery in India under one platform. After intently listening, I distinctly remember his comments — "Raghu, your thoughts are like a 'whiff of fresh air' and if properly implemented, the initiatives that you outlined would bring about a refreshing transformation to the delivery of breast Healthcare in India." 
After this unforgettable chance-meeting with one of the legends in the field of surgical oncology, my "thoughts" became my "Vision". And, there was no looking back, thereafter. Having relocated to India in September 2007, over the past 14 years, I have been working with missionary zeal alongside likeminded colleagues and a proactive government to transform my vision into reality [3].

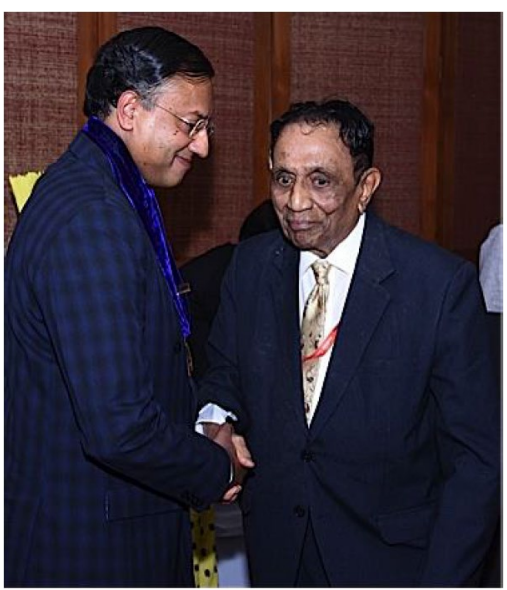

With Prof. Devendra Patel, Founder President ABSI reflecting upon "Mission accomplished" (2017)

Aims of the Editorial are to:

- Outline the developments in the evolution of breast cancer care

- Touch upon the inspiration and genesis of ABSI

- Elaborate in brief, the activities spearheaded by ABSI over the past decade

- Express a wish and hope for the future

\section{Evolution of Breast Cancer Care}

\section{"Change is the only constant in life"}

A number of key developments since the 1980s transformed breast cancer care:

1. Beginning of Population-Based Screening Programmes: Screening mammography has revolutionized early detection and treatment of breast cancer. There is now established evidence that early detection saves lives. Assessment, evaluation and treatment of screendetected cancers have increasingly required the expertise of highly skilled team comprising of radiologist, surgeon and pathologist [4-9].
2. Acceptance of Breast Conserving Surgery: With several randomized controlled trials demonstrating no difference in survival of women undergoing wide local excision (with radiotherapy) versus those undergoing mastectomy, an increasing number of women worldwide are opting for breast conserving surgery. There is now a greater emphasis on how well breast conserving surgery can be done, with importance being given to aesthetic and cosmetic outcome [10-12].

3. Oncoplastic Breast Surgery: One of the most important advances in the past 25 years, with particular reference to breast cancer surgery, is the evolution of the art and science of oncoplastic breast surgery. It is a concept that utilizes oncological skills and plastic surgical techniques (oncoplastic surgery) not only to reshape the conserved breast but also to reconstruct the chest wall following mastectomy. There are recognized training programmes in oncoplastic breast surgery world over, and in recent years, breast cancer care has been enhanced by the emergence of specialist breast surgeon with training in oncoplastic surgical skills — Oncoplastic Breast Surgeon [13-16].

4. Proof that Systemic Treatment Increases Survival: Over the past few decades, there is growing evidence demonstrating significant survival benefit from systemic treatment [17-21].

5. Multidisciplinary Team (MDT) and Breast Cancer Management: As a result of the developments highlighted above, in the early 1990s, multidisciplinary team (MDT) working evolved in the management of breast cancer requiring the expertise of surgeon, radiologist, pathologist, medical oncologist, radiation oncologist and breast care nurse. Multidisciplinary team approach was incorporated and described for the very first time in the management of breast cancer, which is essential to ensure the highest quality care. In fact, this model has since been extended for management of other cancers as well [22-25].

6. Comprehensive Breast Centre Concept: In many developed countries across the world, the concept of "surgical oncologist" has been replaced with "organbased specialists". Examples of organ-based specialists include colorectal surgeons, hepato-pancreatico-bilary surgeons and upper GI surgeons. Breast surgery is now a recognized subspecialty of general surgery abroad with structured training for designated "breast surgeons". In the UK, patients with breast health issues are no longer referred to general surgeons - they are referred to breast surgeons. There is now convincing evidence that diagnosis, management and survival rates of breast cancer are superior when undertaken by dedicated multidisciplinary teams within the confines of Specialist Breast Centres [1, 2, 26-29]. 
A Dedicated Breast Surgical Society in India: the Inspiration!

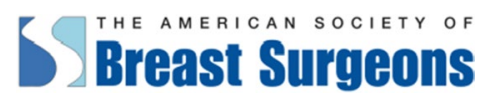

Founded in 1995, the American Society of Breast Surgeons (ASBrS) is the world's first and the single largest Breast Surgical Society that represents some 3000 surgeons, surgical trainees and patient advocates all across America and 50 countries from around the world involved in providing breast cancer care. The Mission of ASBrS is to provide a forum for promoting education, research and development of advanced surgical techniques [30].

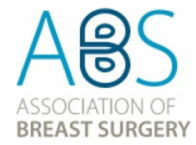

The origins of a dedicated Breast Surgical Society in the UK started around the same time as the ASBrS (1995). Initially referred to as the British Association of Surgical Oncology (BASO) Breast Group, it became the Association of Breast Surgery (ABS) at BASO in 2002. In 2010, ABS separated itself form BASO as an independent charitable organisation. During the early years of its formation in 1995, members were essentially Consultant General Surgeons involved in treating patients with breast disease. As breast surgery evolved to become a distinct specialty in the UK, membership has been extended to other members of the multidisciplinary team [31].

\section{Genesis of the Association of Breast Surgeons of India (ABSI)}

\section{"The best way to predict the future is to create it"}

With well over 162,000 women newly diagnosed with breast cancer every year, breast cancer is the most common cancer affecting women in India. More than $60 \%$ present in advanced stages due to lack of awareness and absence of a robust population-based screening programme. Contrary to the western world where breast cancer is common after the age of 50, the highest incidence of breast cancer in India is between the ages of 40-60 years, at least a decade earlier! More than 87, 000 women succumb to breast cancer every year - a woman dies of breast cancer every $10 \mathrm{~min}$ in India. There are very few dedicated breast centres, and the survival of patients with breast cancer varies across the country $[1,2,32]$.

Inspired by the enormous impact created by ASBrS in the USA and ABS in the UK for well over a decade, I had resolved to replicate this success story in India as well. Since 2004, whilst working in the UK, I had utilized every speaking opportunity in India to highlight the need to nurture a surgical society dedicated to management of breast disease in the country.

\section{“Dreams are a dime a dozen. It's their execution that counts"}

A couple of years after relocating to India, I garnered the explicit support of likeminded colleagues to translate this dream into reality. In 2009, I had submitted a proposal to establish the Association of Breast Surgeons of India (ABSI) as a Section of the Association of Surgeons of India (ASI). Fifty-five ASI members from all across India majorly practicing the art and science of breast surgery seconded my proposal.

\section{ASI Members Who Seconded the Proposal to Establish ABSI}

(Listed in order of allotted ABSI Membership Number).

\begin{tabular}{|c|c|}
\hline Name & City \\
\hline Devendra Patel & Ahmadabad \\
\hline Chintamani & Delhi \\
\hline Diptendra K Sarkar & Kolkata \\
\hline Vishweshwar Shete & Satara \\
\hline Navneet Kaur & New Delhi \\
\hline Thomas Varughese & Cochin \\
\hline Gaurav Agarwal & Lucknow \\
\hline Somashekhar SP & Bangalore \\
\hline Gabriel Sunil Rodrigues & Manipal \\
\hline Raj Kumar & Lucknow \\
\hline Hemant Singhal & Gurgaon \\
\hline Ravi Kant & Delhi \\
\hline Bina Ravi & Delhi \\
\hline Kum Kum Singh & Ajmer \\
\hline Selvi Radha Krishna & Chennai \\
\hline SV Suryanarayana Deo & Delhi \\
\hline Bhartendu Kumar & Muzaffarpur \\
\hline BKC Mohan Prasad & Madurai \\
\hline Kanchan Kaur & Gurgaon \\
\hline Chiranjiva Khandelwal & Patna \\
\hline Subramanyeshwar Rao Thammineedi & Hyderabad \\
\hline Sai Rajendra Sriram & Hyderabad \\
\hline Sai Krishna Vittal & Chennai \\
\hline
\end{tabular}




\begin{tabular}{ll}
\hline Name & City \\
\hline Sai Vishnu Priya Vittal & Chennai \\
Pooja Ramakant & Vellore \\
Paramjit Singh Bakhshi & Jalandhar \\
Vinay Deshmane & Mumbai \\
Anagha Zope & Gandhi Nagar \\
Hari Shukla & Varanasi \\
Anand Kumar Mishra & Lucknow \\
Rajshekhar C Jaka & Bangalore \\
Venkatesh Rao PS & Bangalore \\
Clement Shirodkar Rajan & Bangalore \\
Aashish Mody & Mumbai \\
Ashwin KR & Bangalore \\
Venkata Ramana Murthy Paturi & Vijayawada \\
Arnab Gupta & Kolkata \\
Hemanth Vudayaraju & Hyderabad \\
Sanjay Pandharinath Deshmukh & Pune \\
Krupasindhu Panda & Cuttack \\
Sri Devi Veluswami & Chennai \\
Mallika Tewari & Varanasi \\
Soumya Holla & Bangalore \\
Shabber Zaveri & Bangalore \\
Gurpreet Singh & Chandigarh \\
Pattabhi Ramaiah Kamineni & Vijayawada \\
KVVN Raju Kalidindi & Hyderabad \\
Suresh Anand Nithianand & Chennai \\
MG Rama Rao & Hyderabad \\
Samindra Nath Basak & Kolkata \\
Vijay Pratap Singh & Patna \\
Sabaretnam Mayilvaganan & Bucknow \\
Anantheswara YN & Bangalore \\
Vinay Ravi & \\
Vani Parmar & \\
\hline & \\
& Mumbai \\
\hline
\end{tabular}

\section{"Resistance to change is always the biggest obstacle"}

As expected, there was fierce resistance to the proposal. However, with determined efforts and gentle diplomacy, there was "light at the end of the tunnel" and the General Body of ASI approved the formation of ABSI in december 2010.

And thus, ABSI was born, which is the newest and one of the most vibrant Sections of ASI - the very first organisation in South Asia that represents general surgeons, surgical oncologists and plastic surgeons treating patients with breast disease in India. Over the years, the ABSI membership has steadily increased to become one of the fastest growing
Sections of ASI. Established along similar lines to ASBrS and ABS, the formation of ABSI in many ways is a first step towards developing breast surgery as a distinct subspecialty in India [33].

Unlike ASBrS and ABS, I had deliberately and strategically proposed to launch ASBI as a Section of ASI rather than an independent entity as benign breast disease and breast cancer in India is largely managed by general surgeons. And therefore, general surgeon members of the parent body (ASI) get direct access, exposure and benefit from ABSI's activities.

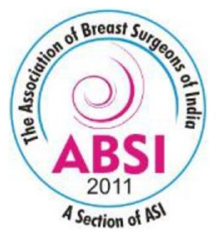

\section{"Leadership is the capacity to translate Vision into Reality"}

The first ad hoc Executive Committee of ABSI was held in Hyderabad in March 2011, where Prof. Devendra Patel (Ahmedabad), me (Hyderabad) and Prof. Diptendra Sarkar (Kolkata) were unanimously elected to serve as Founder President, Founder Honorary Secretary and Founder Honorary Treasurer, respectively.

A lot of thought and deliberation has gone into designing the objectives of ABSI [33], which are:

- To promote the art and science of breast disease in the Indian subcontinent

- To advance standards and training in breast disease amongst members of the medical profession and professions allied to medicine.To formulate structured training including assessment programmes in collaboration with national and international institutions

- To develop breast surgery as a distinct subspecialty in India

- To promote the study and research of breast disease

- To bring out (from time to time) consensus statements regarding the standardized and optimum management of various breast diseases in Indian scenario ["in order to find an Indian solution to Indian problems"]

- To represent surgeons practicing breast surgery on national and international platform

- To create public awareness about the importance of early detection of breast cancer 


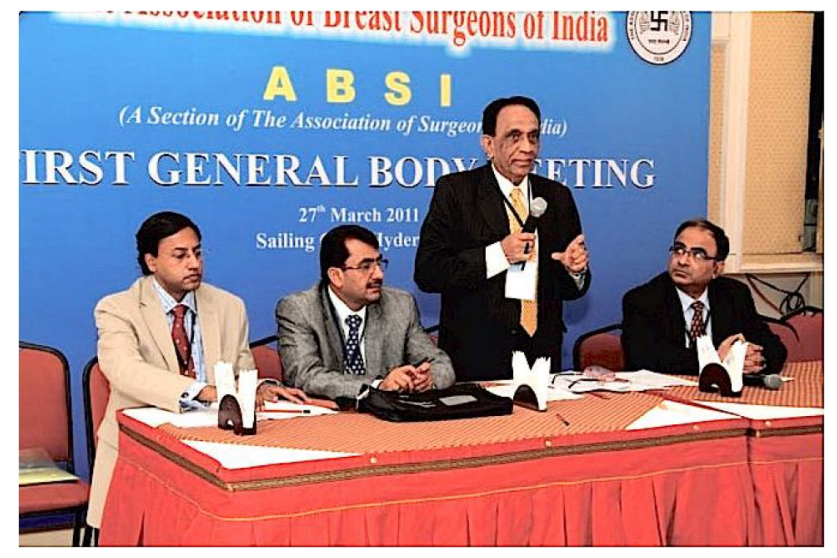

Prof. Devendra Patel, Founder President ABSI addressing the First Annual General Body meeting, Hyderabad (2011)

\section{Principal Office Bearers, ABSI Over the Past Decade (2011-2021)}

\begin{tabular}{llll}
\hline Year & President & Hon. Secretary & Hon. Treasurer \\
\hline $2011-$ & Dr. Devendra Patel & Dr.P.Raghu Ram & Dr. DiptendraSarkar \\
2013 & & & \\
$2013-$ & Dr.Chintamani & Dr. DiptendraSarkar & Dr.S.P. Somashekhar \\
2015 & & & \\
$2015-$ & Dr.P.Raghu Ram & Dr. S.P.Somashekhar & Dr.SVS Deo \\
2017 & & & \\
$2017-$ & Dr.Diptendra Sarkar & Dr. B.C. Ashok & Dr.K.R. Ashwin \\
2019 & & & \\
$2019-$ & Dr. S.P.Somashekhar & Dr. KR Ashwin & Dr Sanjay Jain \\
2021 & & & \\
\hline
\end{tabular}

\section{Annual Conferences (ABSICON)}

The first flagship annual Conference of ABSI was held in Hyderabad in 2012. Subsequent hugely successful ABSI annual meetings that were held in Chandigarh, Kolkata, Indore, Bengaluru, Jaipur and Delhi focused upon on reemphasizing the basics in addition to empowering delegates about oncoplastic techniques and various other latest advances in the art/science of breast surgery. The focus has been on "what one can learn over the weekend that can be implemented on the Monday morning". It would be pertinent to mention here that the ABSI Sectional Meeting venues during the Association of Surgeons of India annual
Conferences (ASICON) have always been packed to capacity, which speaks volumes of the popularity, impact and reach of the Association's academic activities.

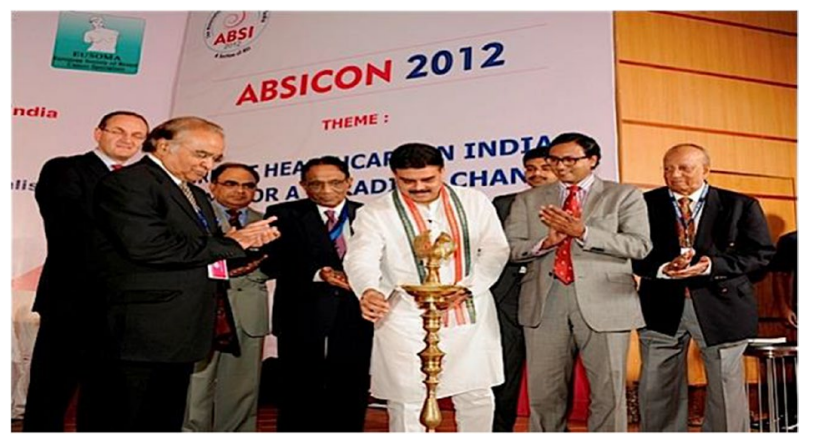

First ABSI annual Congress (ABSICON 2012) held in association with European Society of Breast Cancer Specialists (EUSOMA). Mr Nadendla Manohar, Hon'ble Speaker, Legislative Assembly, Govt. of Andhra Pradesh inaugurating the Congress

\section{Multidisciplinary Course on Breast Imaging [3]}

I was keen to bring to sharp focus, the importance of breast radiologist and breast pathologist, both of whom are integral to the delivery of an efficient breast service. With a specific aim to reach out to radiologists, surgeons and pathologists at developing skills in reading/interpreting breast imaging and correlating it with breast pathology, I invited Prof. Laszlo Tabar, one of the doyens in the field of breast radiology from Sweden to conduct a Pre-Conference Course @ ABSICON 2012. Having organised two hugely successful Tabar's Courses in Hyderabad (2010 and 2011), the Multidisciplinary Course during ABSICON 2012 was the highlight of the Congress, which is still remembered by delegates, well after 9 years!

Up until 2012, the concept of breast radiology was in its infancy in India. Several radiologists from across the country who attended Laszlo Tabar's Courses in Hyderabad (2010, 2011 and 2012) were inspired to form an organisation similar to ABSI. The Breast Imaging Society of India (BISI) was born in 2013 bringing together radiologists with an interest in breast imaging under one umbrella organisation. Over the past 8 years, BISI has inspired several more radiologists to take up breast radiology as a career and has served as a platform for imparting knowledge and skill sets required for a practicing breast radiologist. And thus, the formation of BISI has brought about transformational changes to the delivery of breast radiology services in India. 


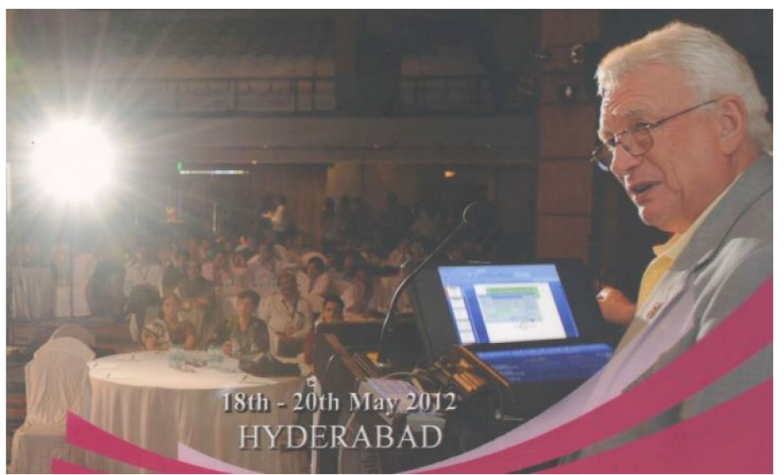

Prof. Laszlo Tabar's Course in Hyderabad during ABSICON 2012

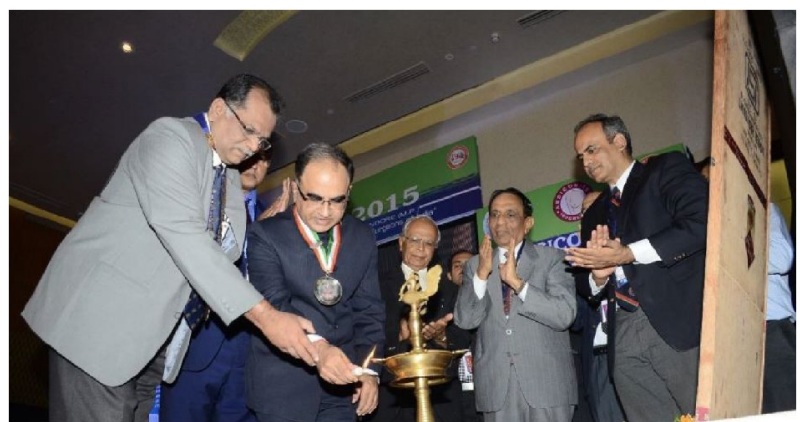

Dr. Santhosh John Abraham, President ASI (2015), and Dr. Chintamani, President ABSI (2013-2015) inaugurating ABSICON 2015

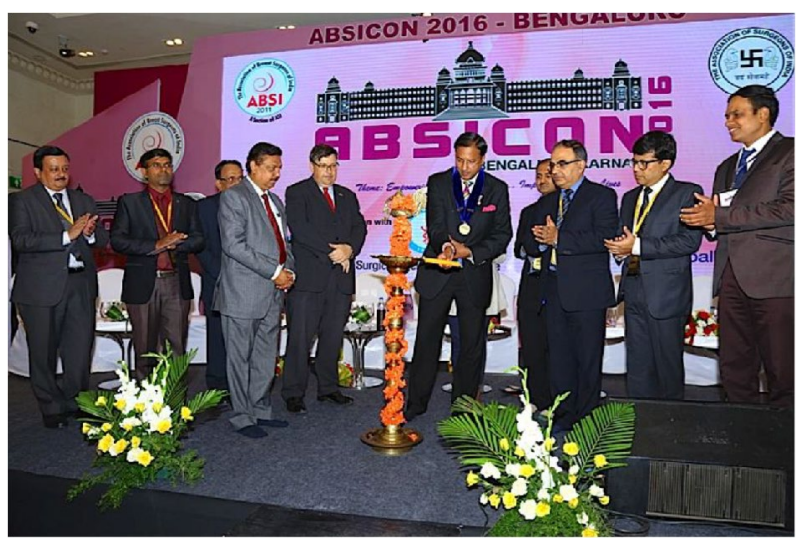

Inaugurating ABSICON 2016, Bengaluru as President ABSI (2015 - 2017)

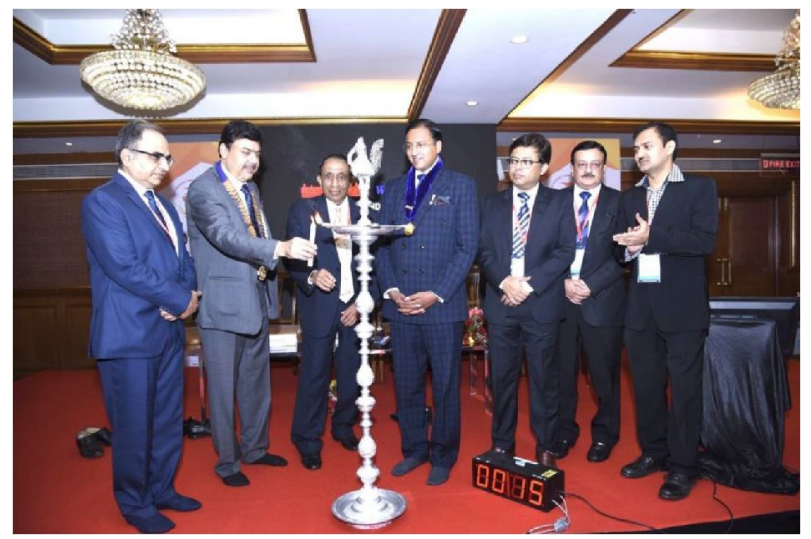

Dr Shiva Misra, President ASI inaugurating ABSICON 2017, Bengaluru

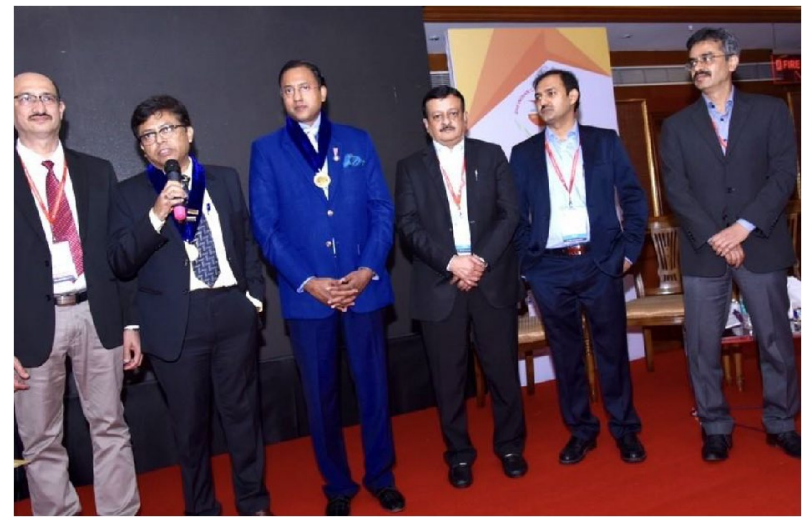

Prof. Diptendra Sarkar, President ABSI (2017-2019) addressing delegates @ ABSICON 2017. Also seen are Principal Office Bearers of ABSI (Prof. Sanjay Jain, Prof. SVS Deo, Prof. S.P. Somashekhar \& Dr. B.C. Ashok) 


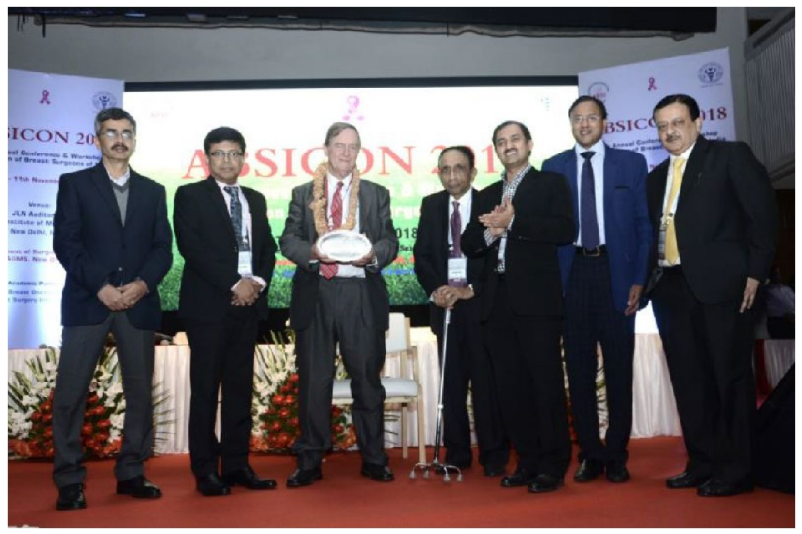

Prof. Robert Mansel after delivering Prof. Devendra Patel Oration during ABSICON 2018 organised by Prof. SVS Deo, Delhi

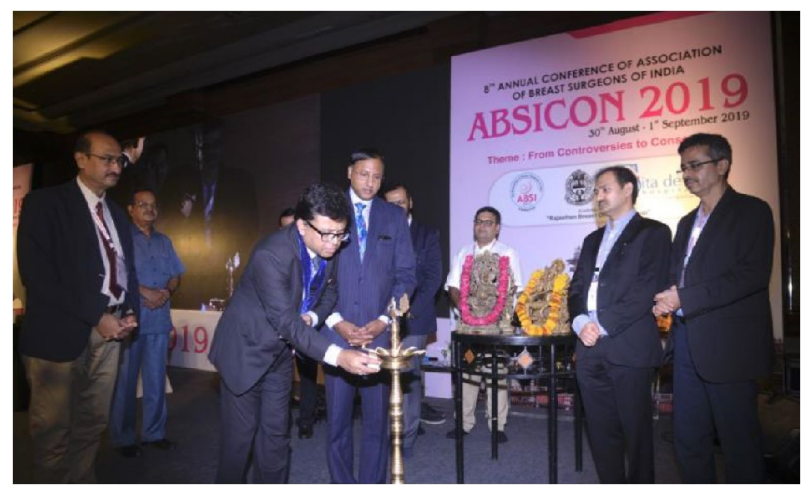

Prof. Diptendra Sarkar, President ABSI (2017-2019) lighting the inaugural lamp @ ABSICON 2019, Jaipur

\section{5 and Beyond: a “New Era”}

\section{"Don't just tell people your dreams... Show them"}

During my Presidential term @ ABSI (2015-2017), several landmark initiatives such as ABSI Training Module, Breast Ultrasound Course for Surgeons, ABSI-UK Fellowship Programme and ABSI Guidelines were carefully planned and implemented. These activities gathered even more momentum during the Presidential terms of Prof. Diptendra Sarkar (2015-2017) and Prof. Somashekhar (2019-2021).

\section{"ABSI Training Module" for surgeons and surgical trainees}

This is a structured training programme, which is being conducted in the cities and towns all over
India since 2015. The aim of this initiative is to empower general surgeons and surgical trainees in every nook and corner of India, particularly in rural areas, about every aspect of breast health explained in simple easy to understand format. Emphasis has been placed upon imparting knowledge required to deliver uniform minimum effective standard of care to patients presenting with breast disease.

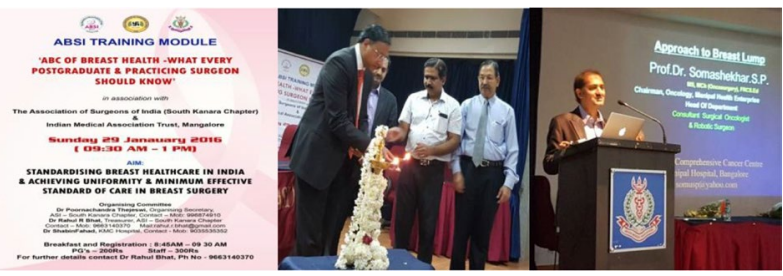

ABSI Training Module organised by ABSI in association with ASI - South Canara Chapter, Mangalore (2017)

\section{Breast Ultrasound Course for Surgeons}

The value of breast imaging for a surgeon practicing breast surgery is similar to importance that a physician gives to a stethoscope. Mirrored upon the successful initiative rolled out by the American Society of Breast Surgeons, ABSI launched Breast Ultrasound Courses with the title - "Breast Imaging - What every Surgeon should know". The aim of these courses implemented all over India under the auspices of ABSI is to impart "hands on" core competency skills in evaluating breast lesions on ultrasound and safely performing ultrasound guided core needle biopsy.

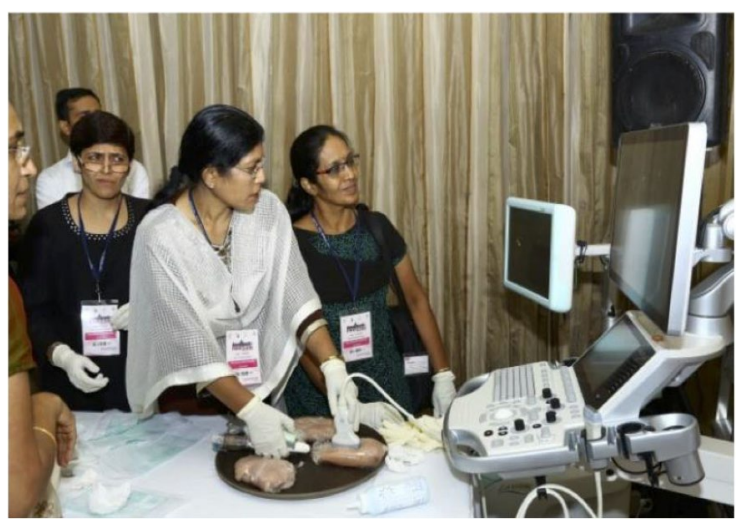

ABSI Breast Ultrasound Course for Surgeons @ ABSICON 2016, Bengaluru (Ultrasound-guided core needle biopsy - practice session) 

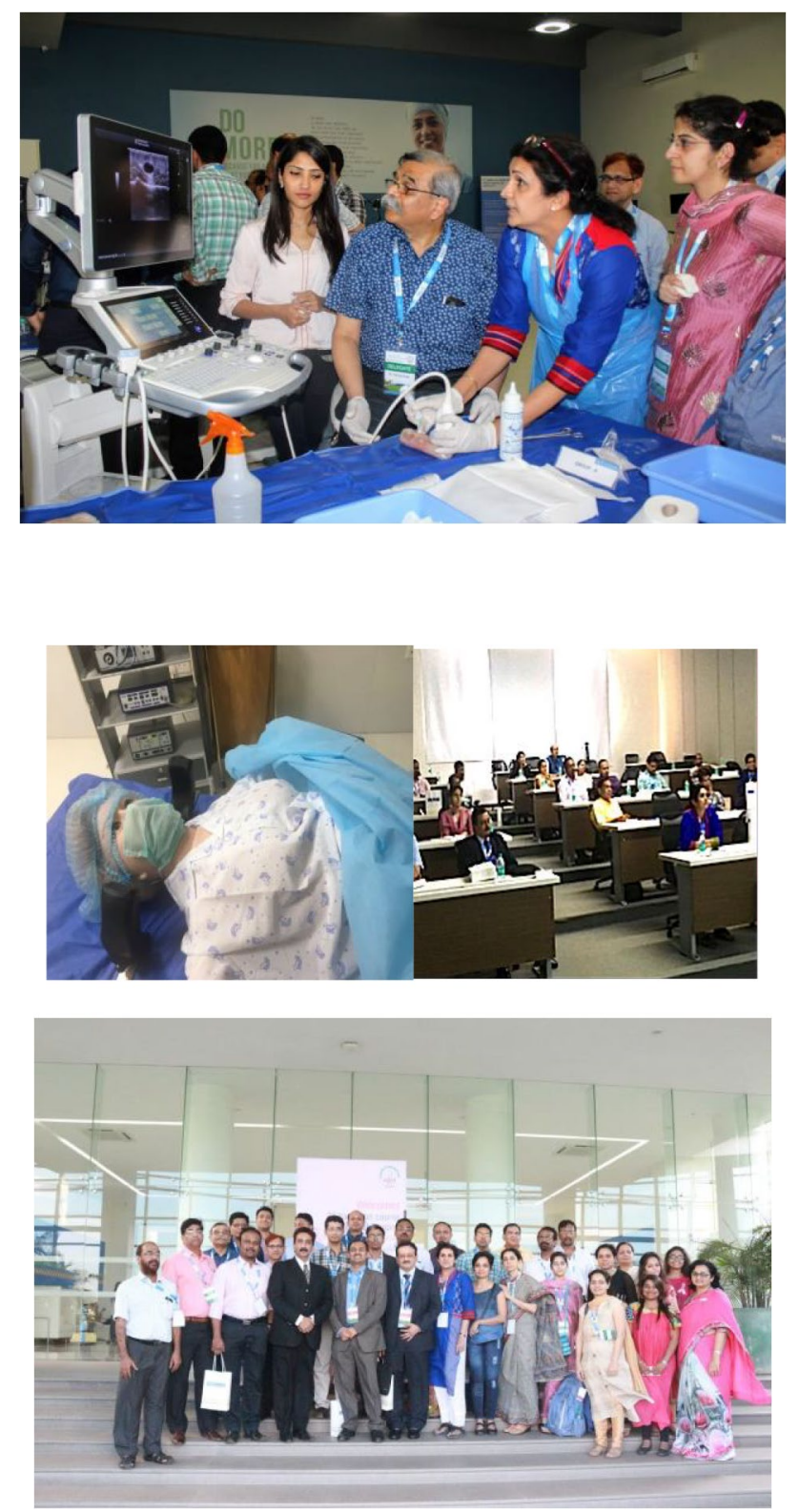

ABSI Breast Ultrasound Course for Surgeons@Meryl Academy, February 2017. Dr. Rupa Ananthasivan, Consultant Radiologist from Manipal Hospitals, Bengaluru conducting the Programme. Also seen are ABSI Principal Office Bearers, Faculty and Participants

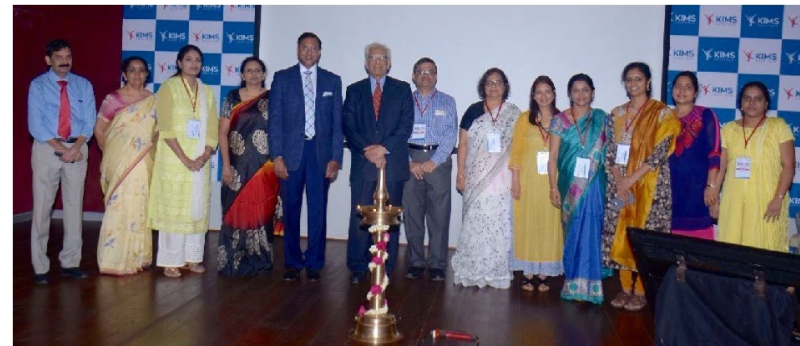

Breast Ultrasound Course held by Breast Imaging Society of India (BISI) in partnership with The Association of Breast Surgeons of India (ABSI), July 2017. BISI Faculty led by Dr Jwala Srikala, Consultant Radiologist@ KIMS Hospitals, Hyderabad

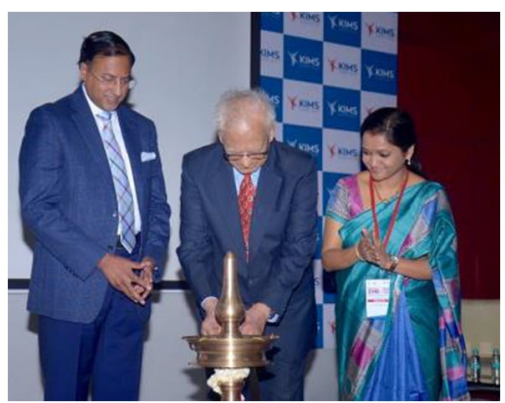

Breast Ultrasound Course inaugurated by world renowned Radiologist Prof. Kakarla Subba Rao

\section{ABSI-UK Travelling Fellowship}

In an endeavour to help, support and encourage bright young surgeons from India to observe "first hand" the art \& science of breast surgery at world renowned centres in the UK, the "ABSI-UK Travelling Fellowship" was launched in 2016. Trainees who have excelled in the "Best paper Sessions" during ABSI annual conferences are selected based upon merit [34].

Through close coordination with the INDO-UK Breast Forum, these trainees undergo a period of "supervised observership" at centres of excellence in the UK [35]. Over the past 5 years, several trainees have been sent to the UK through a generous educational grant from ABSI. These trainees return to India and have been serving as "living bridge" between the UK and India. 


\section{ABSI Guidelines}

To address the huge disparities in breast cancer treatment, which has resulted in "lottery of care", ABSI has brought out guidelines to assist practicing oncologists in India with evidence-based protocols to ensure uniformity in assessment and treatment protocols.

A panel of experts developed a questionnaire similar to the St Gallen's Consensus Panel. The questions addressed every aspect of assessment and treatment. Due care was taken to also include questions relating to limitations that applies to low and middle resource countries.

During the annual Conference of ABSI (ABSICON 2016), questions were flashed onto the screens during a designated primetime session. The expert panel and delegates simultaneously answered these questions using electronic voting pads. The opinion poll was straight away projected on screen. This formed the basis of the "ABSI Consensus Guidelines", which were published in the Indian Journal of Surgery in 2017 [36].

Five years down the line, taking recent evidence into consideration, these guidelines have been redone and feature in this special issue on "breast".

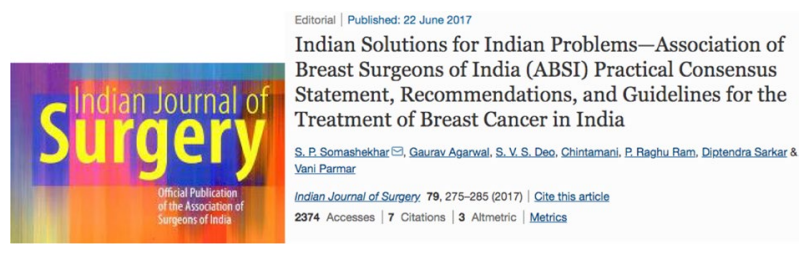

\section{Conclusion}

\section{"You didn't come this far to only come this far"}

From a thought to a vision, and then, translation of vision into reality, ASBI has come a long way. As I reflect upon the Association celebrating 10 positively eventful years, it is heartening to note that much has been achieved.

In the foreseeable future, I look forward to ABSI evolving into a truly multidisciplinary organisation with integration of breast radiologists and breast pathologists in its fold, who are, in fact, the "eyes and ears" to a breast surgeon. To my mind, a first step in this direction would be to conduct meetings/CME programmes and workshops in partnership with the Breast Imaging Society of India (BISI) through a common joint annual academic calendar.

As clinicians involved in delivering breast cancer care, one must not forget the aphorism "To cure sometimes, to relieve often, to comfort always". ABSI must play a lead role in developing the concept of breast care nurses, who should play a pivotal role in supporting, comforting and reassuring patients and their relatives. This aspect of breast cancer care, which is hugely deficient in India, must be given as much importance as is given to assessment and treatment. They too should be integral members of "Team ABSI".

Over the years, although ABSI has partnered with NGOs in conducting a few awareness programmes in the country, there must be even greater emphasis on Breast Cancer Advocacy. Focused efforts by ABSI to empower the citizenry about importance of "Early Detection" would go a long way in saving many lives.

In the fullness of time, it is my wish and desire that breast surgery, breast radiology and breast pathology get their due recognition as distinct subspecialties in India.

In 2031, when ABSI completes 20 glorious years, I am very confident there would be much more to celebrate!

"Incredible things can be done if we are committed to making them happen"

\section{Declarations}

Ethics approval NIL.

Conflict of Interest The authors declare no competing interests.

\section{References}

1. Pillarisetti Raghu Ram (2011) Breast Healthcare in India - time for a paradigm change. Ann R CollSurgEngl (Suppl) 93:250-252

2. Pillarisetti Raghu Ram (2020) Perspective from India: improving breast health Care (Chapter 35) -"Breast Cancer:Global Quality Care", edited by Didier Verhoeven, Cary Kaufman, Robert Mansel, Sabine Siesling, 371-376. Oxford University Press. https:// oxfordmedicine.com/view/10.1093/med/9780198839248.001. 0001/med-9780198839248-chapter-35

3. Pillarisetti, Raghu Ram (2021) United Kingdom to India-a "living bridge": celebrating 25 positively eventful years (19962021). Indian J Surg. https://doi.org/10.1007/s12262-021-02806-1

4. Duffy SW, Smith RA, Tabár L, Dean PB, Chen TH (2019) The incidence of fatal breast cancer measures the increased effectiveness of therapy in women participating in mammography screening. Cancer 125(4):515-523

5. Duffy Stephen W, LászlóTabár Amy Ming-Fang, Yen Peter B, Dean $M$ et al (2020) Mammography screening reduces rates of advanced and fatal breast cancers: results in 549,091 Women. Cancer 126:2971-2979

6. Tabar L, Fagerberg CJ, Gad A et al (1985) Reduction in mortality from breast cancer after mass screening with mammography. Randomised trial from the Breast Cancer Screening Working Group of the Swedish National Board of Health and Welfare. Lancet 1:829-32

7. Moss SM, Cuckle H, Evans A et al (2006) Effect of mammographic screening from age 40 years on breast cancer mortality at 10 years' follow-up: a randomised controlled trial. Lancet 368:2053-2060 
8. Smith RA, Duffy SW, Gabe R et al (2004) The randomized trials of breast cancer screening: what have we learned? RadiolClin North Am 42:793-806

9. Tabar L, Vitak B, Chen TH et al (2011) Swedish two-county trial: impact of mammographic screening on breast cancer mortality during 3 decades. Radiology 260:658-663

10. Early Breast Cancer Trialists' Collaborative Group (1995) Effects of radiotherapy and surgery in early breast cancer: an overview of the randomised trials. N Engl J Med 333:1444-1455

11. Morris AD, Morris RD, Wilson JF et al (1997) Breast conserving therapy versus mastectomy in early stage breast cancer: a metaanalysis of 10year survival. Cancer J Sci Am 3:6-12

12. Van Maaren MC, de Munck L, de Bock GH et al (2016) 10-year survival after breast-conserving surgery plus radiotherapy compared with mastectomy in early breast cancer in the Netherlands: a population-based study. Lancet Oncol 17(8):1158-1170

13. Clough KB, Kaufman GJ, Nos C et al (2010) Improving breast cancer surgery: a classification and quadrant per quadrant atlas for oncoplastic surgery. Ann Surg Oncol 17(5):1375-1391

14. Savalia NB, Silverstein MJ (2016) Oncoplastic breast reconstruction: patient selection and surgical techniques. J Surg Oncol 113(8):875-882

15. Pillarisetti Raghu Ram, Guidubaldo Querci Della Rovere (2009) Oncoplastic breast surgery, recent advances in surgery, Vol.32; Chapter 2, 11-26. Edited by Prof. Irving Taylor \& CD Johnson, Royal Society of Medicine Publication, London. https://www.taylo rfrancis.com/chapters/edit/10.1201/b13291-3/oncoplastic-breastsurgery-raghu-ram-pillarisetti-guidubaldo-querci-della-rovere

16. Pillarisetti Raghu Ram (2012) Guidubaldo Querci della Rovere: oncoplastic breast surgery (Review article). Indian J Surgery 74(3):255-263

17. Early Breast Cancer Trialists' Collaborative Group (2012) Comparisons between different polychemotherapy regimens for early breast cancer: meta-analyses of long-term outcome among 100,000 women in 123 randomised trials. Lancet 379(9814):432-444

18. Perez EA, Romond EH, Suman VJ et al (2011) Four-year follow-up of trastuzumab plus adjuvant chemotherapy for operable human epidermal growth factor receptor 2-positive breast cancer: joint analysis of data from NCCTG N9831 and NSABP B-31. J ClinOncol 29(25):3366-3373

19. Houssami N, Macaskill P, von Minckwitz G et al (2012) Metaanalysis of the association of breast cancer subtype and pathologic complete response to neoadjuvant chemotherapy. Eur J Cancer 48(18):3342-3354

20. Davies C, Godwin J, Gray R et al (2011) Relevance of breast cancer hormone receptors and other factors to the efficacy of adjuvant tamoxifen: patient- level meta-analysis of randomised trials. Lancet 378(9793):771-784
21. Spring LM, Gupta A, Reynolds KL et al (2016) Neoadjuvant endocrine therapy for estrogen receptor-positive breast cancer: a systematic review and meta-analysis. JAMA Oncol 2(11):1477-1486

22. Cancer Guidance Sub-group of the Clinical Outcomes Group (1996) Improving outcomes in breast cancer. Department of Health, London

23. Provision of breast services in the UK (1995) the advantages of specialist breast units. Churchill Livingstone, Report of a working party of the British Breast Group. Edinburgh

24. The Breast Surgeons Group of the British Association of Surgical Oncology (1995) Guidelines for surgeons in the management of symptomatic breast disease in the United Kingdom. BASO, London

25. A policy framework for commissioning cancer services (1995) Department of Health - Calman-Hine Cancer report. https://webar chive.nationalarchives.gov.uk/ukgwa/20130123204024/http:// www.dh.gov.uk/en/Publicationsandstatistics/Publications/Publi cationsPolicyAndGuidance/DH_4071083

26. Biganzoli L, Cardoso F, Beishon M, Cameron D et al (2020) The requirements of a specialist breast centre. Breast 51:65-84

27. Early and locally advanced breast cancer: diagnosis and treatment, Nice Guidelines, UK (updated 2018). https://www.nice.org.uk/ guidance/ng101/chapter/Recommendations\#referral-diagnosisand-preoperative-assessment. Accessed 14 Sept 2021

28. Sainsbury R, Haward B, Rider L et al (1995) Influence of clinician workload and patterns of treatment on survival from breast cancer. Lancet 345:1265-1270

29. Silverstein M (2000) SurgClin N Am 9(2):159-175

30. The American Society of Breast Surgeons website (https://www. breastsurgeons.org/). Accessed 14 Sept 2021

31. The Association of Breast Surgery website (https://associationofbr eastsurgery.org.uk/). Accessed 14 Sept 2021

32. Dhillon PK, Mathur P, Nandakumar A (2018) The burden of cancers and their variations across the states of India: the global burden of disease study 1990-2016. Lancet Oncol 19:1289-1306

33. The Association of Breast Surgeons of India website (http://absi. in/). Accessed 14 Sept 2021

34. The Association of Breast Surgeons of India website (http://absi. in/rules/). Accessed 14 Sept 2021

35. The Association of Breast Surgeons of India website (http://absi. in/report-from-candidates/). Accessed 14 Sept 2021

36. Somashekhar SP, Agarwal G, Deo SVS et al (2017) Indian solutions for Indian problems-association of breast surgeons of India (ABSI) practical consensus statement, recommendations, and guidelines for the treatment of breast cancer in India. Indian J Surg 79:275-285. https://doi.org/10.1007/s12262-017-1666-3

Publisher's Note Springer Nature remains neutral with regard to jurisdictional claims in published maps and institutional affiliations. 